\title{
Subcutaneous Leiomyosarcoma Metastasized to the Lymph Nodes Involved with Small Lymphocytic Lymphoma / Chronic Lymphocytic Leukemia
}

\author{
Ayfer KAMALI POLAT ${ }^{1}$, Atilla SORAN ${ }^{2}$, Amal KANBOUR-SHAKIR ${ }^{3}$, Howard EDINGTON ${ }^{2}$ \\ ${ }^{1}$ Department of General Surgery, Ondokuz Mayıs University, Faculty of Medicine, SAMSUN, TURKEY, \\ Departments of ${ }^{2}$ Surgical Oncology and ${ }^{3}$ Pathology, Pittsburgh University, UPMC, Pittsburgh PA, USA
}

\begin{abstract}
Herein, we present a case of a 76-year-old Caucasian man with a very large fungating, ulcerating mass, involving the right neck and parotid area, which developed while he was being treated for chronic lymphocytic leukemia/small lymphocytic lymphoma. Resection of the fungating right neck tumor, right modified radical neck dissection, and right superficial parotidectomy with flap reconstruction were performed. The final pathological diagnosis was high-grade leiomyosarcoma of the skin and the subcutaneous tissue, with invasion into the skeletal muscle, skin, and soft tissue. Additionally, the sarcoma had metastasized to the lymph nodes that were involved diffusely by lymphoma. The most interesting fact for this case is coincidence of three rare occurrences which were soft tissue sarcomas of subcutaneous leiomyosarcoma form and its metastasis to same lymph nodes that were involved with lymphoma.
\end{abstract}

Key Words: Leiomyosarcoma, Chronic lymphocytic leukemia, Lymph node, Metastasis

\section{INTRODUCTION}

Leiomyosarcomas (LMS) are rare malignant tumors originating in the smooth muscles, and constitute $3-7 \%$ of all soft tissue sarcomas (1-3). The LMS arising in the dermis and subcutis are referred to as cutaneous and subcutaneous LMS, respectively $(3,4)$. LMS usually appear as solitary nodules and commonly occur on the lower extremities (50$70 \%)$, followed by the upper extremities (20-30\%), trunk (10-15\%), and head and neck (1-5\%). Soft tissue sarcomas of the head and neck in adults are rare. They account for approximately $10 \%$ of all soft tissue sarcomas and less than $1 \%$ of all head and neck tumors (1). In this report, we present a case of two different malignancies in the same lymph node, in addition to the rare localization of LMS.

\section{CASE REPORT}

A 76-year-old Caucasian man with chronic lymphocytic leukemia/small lymphocytic lymphoma (CLL/SLL) was being treated with two cycles of chemotherapy. During treatment, an enormous fungating $12,0 \mathrm{~cm}$ tumor covering much of the right auricular and upper neck area with black ulcerated nodules, which caused bleeding at the postauricular area, had developed. He had palpable lymph nodes on both sides of his cervical area, bilateral bulky nodes on the axillary areas, as well as trochlear nodes and

(Turk Patoloji Derg 2017, 33:244-247)

Received : 04.03.2011 Accepted : 19.05.2011 groin lymph nodes. Right axillary lymph node excisional biopsy disclosed small lymphocytic lymphoma/chronic lymphocytic leukemia (CLL/SLL); and cells positive for CD20, CD5, CD23, and CD38; negative for CD3, CD10, Cyclin D1and ZAP-70. Bone marrow aspirate and biopsy disclosed SLL/CLL/SLL without any phenotypic evidence of transformation to a higher grade lymphoid neoplasm.

Cytogenetics disclosed 80\% abnormal B cells. Fluorescence in situ hybridization results revealed a karyotype of $43 \mathrm{XY}$ with monosomy 13 and absence of MYB (myeloblastosis) gene deletion, loss of ATM (ataxia telangiectasia mutated), p53 (protein 53) tumor gene suppression, trisomy 12, and $\mathrm{IgH}$ (immunoglobulin heavy locus ${ }^{1}$ ) gene rearrangement, which is equal to no abnormality of chromosome 17 . This pattern, in general, suggests a favorable prognosis for CLL/SLL. Fluorodeoxyglucose $\left({ }^{18} \mathrm{~F}, \mathrm{FDG}\right)$ scan of several bulky FDG-avid cervical nodes were obtained. Within the subcutaneous soft tissue of the posterior neck, innumerable enlarged bilateral axillary lymph nodes; mediastinal, abdominal, inguinal, and internal and external iliac lymph nodes; cardiophrenic and costophrenic lymph nodes; an intermediate 4-mm right middle lobe pulmonary nodule; and mild splenomegaly demonstrating increased metabolic activity were seen. Positron emission tomographycomputed tomography showed no evidence of malignancy.

Correspondence: Ayfer KAMALI POLAT

Ondokuz Mayıs Üniversiitesi, Tip Fakültesi, Genel Cerrahi Anabilim Dalı,

SAMSUN, TURKEY

E-mail: ayferkp@yahoo.com Phone: +90 5324457195 
The obtained findings gave an initial impression of locally advanced skin cancer, melanoma versus squamous cell carcinoma, but most findings were clinically closer to the appearance of melanoma. The first biopsy was performed using a 3-mm punch biopsy, which failed to confirm the exact histology. Thus, a misdiagnosis of atypical fibroxanthoma was made. Since this lesion was growing despite chemotherapy with bendamustine and rituximab, the diagnosis of the first biopsy was thought to be a sampling error. At this point, surgical extirpation was recommended. After 2 cycles of bendamustine and rituximab, resection of the fungating right neck tumor, right modified radical neck dissection, and right superficial parotidectomy with flap reconstruction were performed.

Histologically, a highly pleomorphic infiltrative neoplasm with vague fascicular pattern that abutted but did not involve the epidermis was observed. The tumor cells were predominantly large, round to rhomboid with abundant eosinophilic cytoplasm and large ovoid vesicular nuclei with prominent irregular nucleoli (Figure 1A). Necrosis with a mitotic rate of approximately 5/10 in high-power fields was identified. Immunohistochemistry revealed tumor cells to be strongly and diffusely positive for desmin and caldesmon. CD68 was positive within intratumoral macrophages. The tumor cells showed weak cytoplasmic positivity for S100, but were negative for cytokeratin AE1/3, AMA, CD34, tyrosinase, HMB45, and Melan A (Figure 1B). These findings supported the diagnosis of LMS.

The tumor size in greatest dimension was $12.0 \mathrm{~cm}$, followed by an additional dimension of $7.0 \mathrm{~cm}$. The final pathological diagnosis was high-grade LMS of the skin and the subcutaneous tissue with invasion into the skeletal muscle, as well as metastatic LMS in multiple lymph nodes. The LMS metastasized to multiple lymph nodes that were also involved with CLL/SLL (Figure 2A-C). The mitotic rate was $5 / 10$ in high-power fields. There was no macroscopic necrosis but microscopic necrosis was present in 15\% of the nodes. The grade was set to be 3 according to the French Federation of Cancer Centers Sarcoma Group. The pathologic staging was pT2a, pN1 $(3+/ 15) \mathrm{Mx}, \mathrm{G} 3$. The margin was uninvolved by sarcoma, and the closest margin was $0.1 \mathrm{~cm}$

\section{DISCUSSION}

Soft tissue sarcoma of the head and neck in adults is rare. Sarcomas are characterized by local invasion and their pattern of metastasis is mostly hematogenous. Lymph node metastases are uncommon. The rate of regional lymph nodes metastasis of LMS was reported to be $2.7-15 \%$ (1-4).

Few cases of synchronous lymph node involvement of different kinds of tumors concomitant with lymphoproliferative disorders or other malignancies have been reported in the literature (5-9). Most of them involve CLL/SLL and different kinds of cancers such as cutaneous malignant neoplasm expressing the Langerhans cell phenotype, dendritic cell tumor, malignant melanoma, oropharyngeal squamous cell carcinoma, colon carcinoma, and squamous cell carcinoma of the uterine cervix (6-8, 10-13). Immunosuppression may predispose CLL/SLL patients to a high risk of second malignancies $(11,14)$. Irradiation, alkylating agent chemotherapy, and antimetabolite use have been identified as risk factors that potentiate second malignancies $(15,16)$. The monoclonal antibody rituximab has been previously linked to second malignancies $(17,18)$, and rituximab was one of

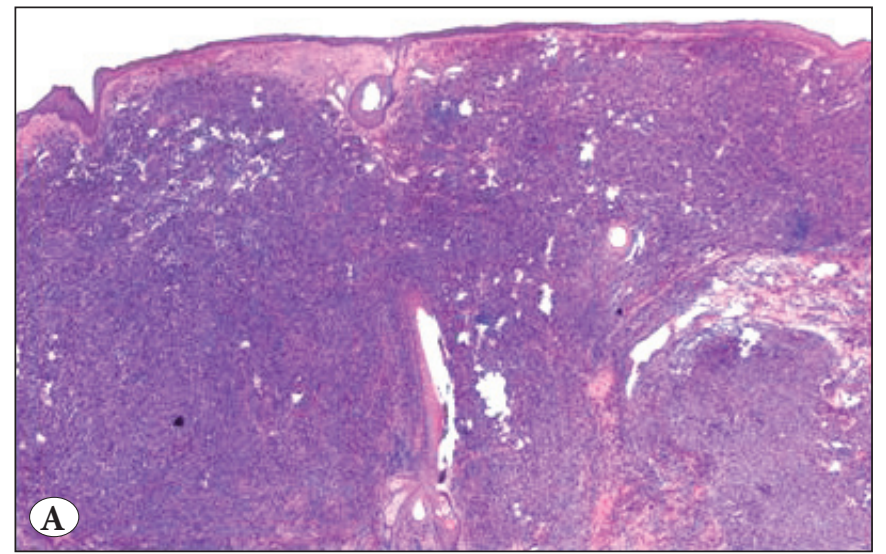

Figure 1: A) Leiomyosarcoma involving the skin (H\&E; $\mathrm{x} 2)$; B) Upper (H\&E; x20), lower right (desmin and caldesmon, x20), lower left (CK AE1/AE3, x20).

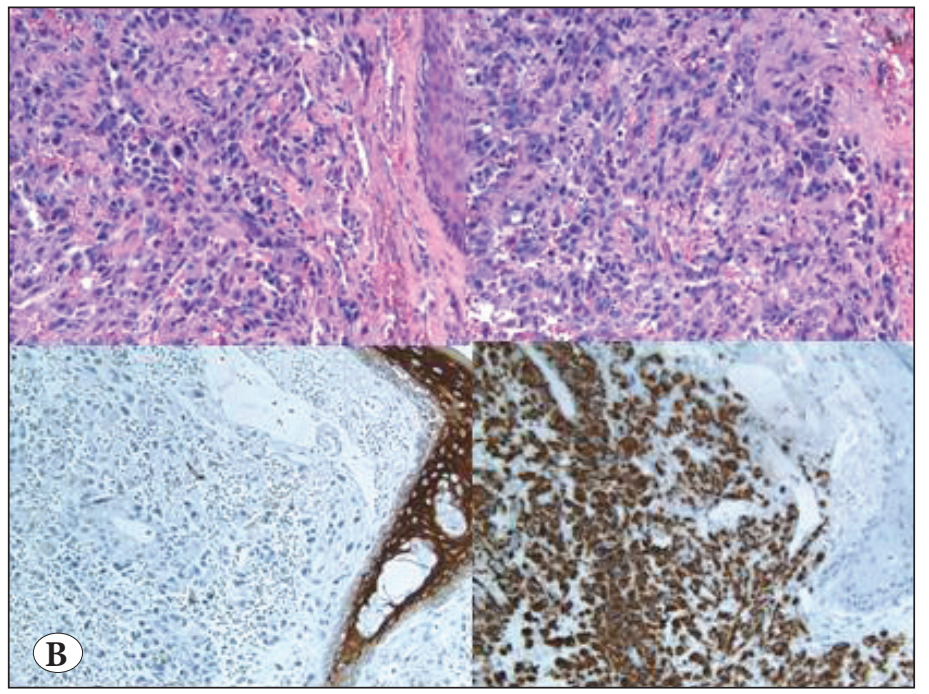



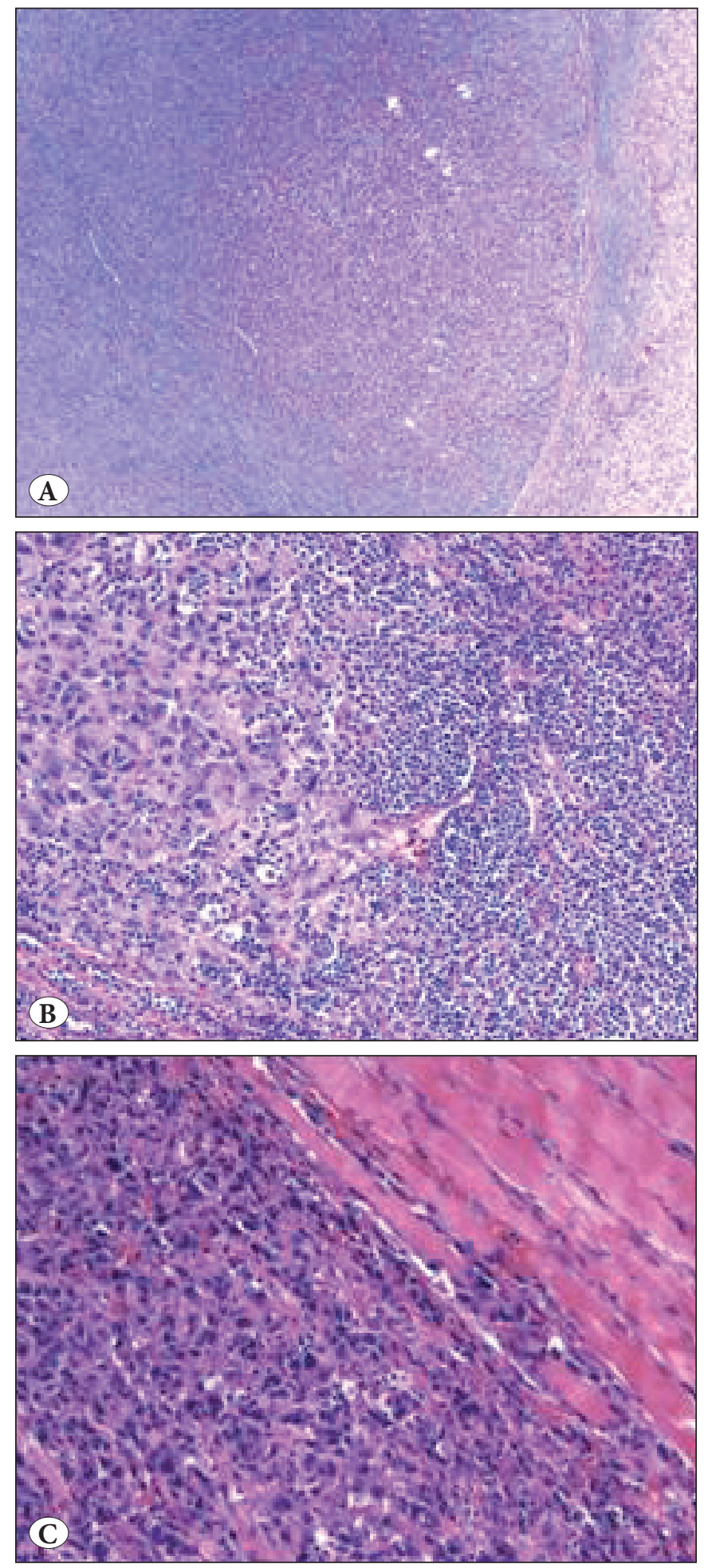

Figure 2: A, B) Metastatic leiomyosarcoma to lymph node involved with CLL/SLL (right-H\&E, x20; left-H\&E, x4); C) Leiomyosarcoma infiltrating skeletal muscle (H\&E, x20). the medications of our patient. Congyang et al. reported a case of synchronous histiocytic sarcoma (HS) and diffuse large B cell lymphoma (DLBL) involving the stomach (19). According to immunohistochemical results of their study; HS and DLBL co-expressed Oct-2, Bcl-2, and Bcl-6, they suggest that HS may share a common origin with DLBL, or be transdifferentiated from DLBL (19). Bonetti et al. described two distinctive malignancies, cutaneous neoplasm and chronic lymphocytic leukemia, in a single lymph node at the inguinal region (8). Demellawy et al. reported a case of synchronous malignant melanoma and CLL/SLL in the same lymph node (20). To our knowledge, this is the first report of cutaneous LMS and CLL/SLL existing synchronously at the same lymph nodes.

Accurate diagnosis and histological classification with adequate sampling is critical for treating soft tissue tumors as cytological and architectural features may be inadequate to distinguish the different sarcomas, particularly if they are poorly differentiated. In the present case, the initial clinical impression was locally advanced skin cancer, leading to a misdiagnosis of atypical fibroxanthoma based on punch biopsy. The correct final diagnosis was made after wide surgical excision and lymph node dissection.

In conclusion, we reported here our encounter with a case of synchronous occurrence of three rare phenomena: soft tissue sarcoma presenting as LMS, involvement of the head and neck region and the metastasis of the leiomyosarcoma to the same lymph node affected by lymphoma.

\section{REFERENCES}

1. Robbins Basic Pathology. In: Kumar V, Abbas AK, Fausto N, Mitchell RN, editors. 8th ed. Soft tissue tumors. Elsevier; 2007. 837.

2. Sumida T, Hamakawa H, Otsuka K, Tanioka H. Leiomyosarcoma of the maxillary sinus with cervical lymph node metastasis. J Oral Maxillofac Surg. 2001;59:568-71.

3. Skoulakis C, Chimona TS, Tsirevelou P, Papadakis CE. Subcutaneus leiomyosarcoma of the neck: A case report. Cases J. 2010;3:52.

4. Murray F Brennan, Kaled M Alektiar, Robert G. Cancer; Principles and practice of oncology. In: Devita VT, Hellman S, Rosenberg SA, editors. Soft tissue sarcoma. 6th ed. Lippincott Williams \& Wilkins; 2001.1841-91.

5. Cossu A, Deiana A, Lissia A, Dedola MF, Cocco L, Palmieri G, Tanda F. Synchronous interdigitating dendritic cell sarcoma and B-cell small lymphocytic lymphoma in a lymph node. Arch Pathol Lab Med. 2000;130:544-7.

6. McElroy C, Velilla R, Chaudhary H, Al-Abbadi MA. Fine-needle aspiration diagnosis of squamous cell carcinoma in a lymph node involved with small lymphocytic lymphoma: Case report and review of the literature. Diagn Cytopathol. 2009;37:48-50. 
7. Quilon JM, Day S, Lasker JC. Synchronous tumors: Hodgkin disease presenting in mesenteric lymph nodes from a right hemicolectomy for colon carcinoma. South Med J. 2004;97:11335 .

8. Bonetti F, Knowles DM 2nd, Chilosi M, Pisa R, Fiaccavento S, Rizzuto N, Zamboni G, Menestrina F, Fiore-Donati L. A distinctive cutaneous malignant neoplasm expressing the Langerhans cell phenotype. Synchronous occurrence with B-chronic lymphocytic leukemia. Cancer. 1985;55:2417-25.

9. Vasef MA, Zaatari GS, Chan WC, Sun NC, Weiss LM, Brynes RK. Dendritic cell tumors associated with low-grade B-cell malignancies. Report of three cases. Am J Clin Pathol. 1995; 104:696-701.

10. Flezar MS, Prevodnik VK, Kirbis IS, Strojan P. Cutaneous squamous cell carcinoma metastatic to chronic lymphocytic leukaemia: Diagnostic potential of fine needle aspiration cytology. Cytopathology. 2006;17:288-294.

11. Mehrany K, Weenig RH, Lee KK, Pittelkow MR, Otley CC. Increased metastasis and mortality from cutaneous squamous cell carcinoma in patients with chronic lymphocytic leukemia. J Am Acad Dermatol. 2005;53:1067-71.

12. Mikami Y, Maehata K, Fujiwara K, Sasano H. Squamous cell carcinoma of the uterine cervix in association with stage 0 chronic lymphocytic leukemia/small lymphocytic lymphoma. Gynecol Oncol. 2004;92:974-7.

13. Amamoo DG, Moayeri H, Takita H, Han T. Bronchogenic carcinoma in chronic lymphocytic leukemia. Chest. 1979;75: 174-7.

14. Koreishi AF, Saenz AJ, Arcila ME, Hedvat C, Fleming S, TeruyaFeldstein J. Synchronous Follicular Lymphoma, Kaposi Sarcoma, and Castleman's Disease in a HIV-negative patient with EBV and HHV-8 coinfection. Int J Surg Pathol. 2011;19:685-91.
15. Ng AK, Travis LB. Subsequent malignant neoplasms in cancer survivors. Cancer J. 2008;14:429-34.

16. Renard M, Suciu S, Bertrand Y, Uyttebroeck A, Ferster A, van der Werff Ten Bosch J, Mazingue F, Plouvier E, Robert A, Boutard P, Millot F, Munzer M, Mechinaud F, Lescoeur B, Baila L, Vandecruys E, Benoit Y, Philippet P; EORTC Children Leukaemia Group (CLG) Second neoplasm in children treated in EORTC 58881 trial for acute lymphoblastic malignancies: Low incidence of CNS tumours. Pediatr Blood Cancer. 2011;57:119-25.

17. Tarella C, Passera R, Magni M, Benedetti F, Rossi A, Gueli A, Patti C, Parvis G, Ciceri F, Gallamini A, Cortelazzo S, Zoli V, Corradini P, Carobbio A, Mulé A, Bosa M, Barbui A, Di Nicola M, Sorio M, Caracciolo D, Gianni AM, Rambaldi A. Risk factors for the development of secondary malignancy after high-dose chemotherapy and autograft, with or without rituximab: A 20 year retrospective follow-up study in patients with lymphoma. J Clin Oncol. 2011;29:814-24.

18. Aksoy S, Arslan C, Harputluoglu H, Dizdar O, Altundag K. Malignancies after rituximab treatment: Just coincidence or more? J BUON. 2011;16:112-5.

19. Congyang L, Xinggui W, Hao L, Weihua H. Synchronous histiocytic sarcoma and diffuse large B cell lymphoma involving the stomach: a case report and review of the literature. Int J Hematol. 2011;93:247-52.

20. Demellawy ED, Ross C, Sur M, Alowami S. Synchronously diagnosed lymph nodal collision tumor of malignant melanoma and chronic lymphocytic leukemia/small lymphocytic lymphoma: Case report. Diagn Pathol. 2007;2:34. 